\title{
Effects of Disinfection of Combined Agar/Alginate Impressions on the Dimensional Accuracy of Stone Casts
}

\author{
Hisako HIRAGUCHI ${ }^{1,2}$, Hisami NAKAGAWA ${ }^{3}$, Masahiro KAKETANI ${ }^{1,2}$, Hideharu HIROSE ${ }^{1,2}$ and Minoru \\ NISHIYAMA ${ }^{1,2}$ \\ ${ }^{1}$ Department of Dental Materials, Nihon University School of Dentistry, 1-8-13 Kanda-Surugadai, Chiyoda-ku, Tokyo 101- \\ 8310, Japan \\ ${ }^{2}$ Division of Biomaterials Science, Dental Research Center, Nihon University School of Dentistry, 1-8-13 Kanda-Surugadai, \\ Chiyoda-ku, Tokyo 101-8310, Japan \\ ${ }^{3}$ Dental Research Center, Nihon University School of Dentistry, 1-8-13 Kanda-Surugadai, Chiyoda-ku, Tokyo 101-8310, Japan \\ Corresponding author, Hisako HIRAGUCHI; E-mail: hiraguchi@dent.nihon-u.ac.jp
}

Received September 25, 2006 /Accepted February 8, 2007

\begin{abstract}
This study investigated the effects of disinfection of combined agar/alginate impressions on the dimensional accuracy of resultant stone casts. Impressions of a master cast designed to simulate an abutment tooth were prepared by combining each of two brands of cartridge-form agar impression materials with an alginate impression material. The impressions were immersed in $1 \%$ sodium hypochlorite for 10 minutes or $2 \%$ glutaraldehyde for 30 minutes. The remaining impressions were sprayed with these two disinfectants and then stored in sealed bags for 10, 30, 60, and 120 minutes. Stone casts obtained from the non-disinfected impressions were also prepared as control. Changes in diameter of the stone casts were then measured. Results indicated that storage for 10 minutes after spraying with 1\% sodium hypochlorite was an appropriate disinfection method for combined agar/alginate impressions, as well as immersion in $1 \%$ sodium hypochlorite for 10 minutes.
\end{abstract}

Keywords: Agar impression material, Alginate impression material, Disinfection

\section{INTRODUCTION}

Impressions and stone casts have to be disinfected to prevent transmission of infectious diseases during dental treatment ${ }^{1-3)}$. Previously, we investigated the effects of disinfection of alginate impressions on resultant stone casts in terms of surface quality, dimensional accuracy, and deformation ${ }^{4.8}$. In the present study, we sought to examine the disinfection effects of combined agar/alginate impressions on the dimensional accuracy of stone casts.

Combined agar/alginate impressions are commonly used in dental clinics, and they need to be disinfected without negative effect. The immersion of combined agar/alginate impressions in $1 \%$ and $0.5 \%$ sodium hypochlorite solutions for 15 minutes has been reported to slightly affect the dimensional accuracy of stone casts ${ }^{9-11}$. To date, information is scarce concerning spray disinfection. When compared to immersion disinfection, the effect on the dimensional accuracy of stone casts - arising the storage of agar or alginate impression after spraying with disinfectants - is minimal ${ }^{12,13)}$. In addition, the alginate impression characterized by smaller dimensional change in $100 \%$ relative humidity can be stored for a long time after spraying with disinfectants ${ }^{8,14}$.

Against this background, we sought to investigate the possibility of spraying disinfection of combined agar/alginate impressions with minimal effect on the dimensional accuracy of stone casts. The present study evaluated the dimensional change of stone casts obtained from impressions treated by spray disinfection as compared with that of immersion disinfection.

\section{MATERIALS AND METHODS}

\section{Materials used}

Table 1 lists the materials which were used according to the instructions of the respective manufacturers. Two brands of cartridge-form agar impression material (ARO: Aromaloid and AJI: Ajisai, Omnico, Tokyo, Japan) were boiled for 10 minutes and then stored at $63^{\circ} \mathrm{C}$ in a dry conditioner (Melty, Morita, Tokyo, Japan). Using an automatic mixer (Rakuneru, GC, Tokyo, Japan), alginate impression material (ACZ: Algiace Z, Dentsply-Sankin, Tokyo, Japan) and type $\mathrm{V}$ dental stone (New Plastone, GC, Tokyo, Japan) were mixed with $\mathrm{W} / \mathrm{P}$ ratios of 2.27 and 0.24 , respectively. Disinfectants used were $1 \%$ sodium hypochlorite solution (SH) and 2\% glutaraldehyde solution (GA). The disinfectants, Purelox (Oyalox, Tokyo, Japan) and Sterihyde (Maruishi Pharmaceutical, Osaka, Japan), were diluted with deionized water to concentrations of $1 \%$ and $2 \%$, respectively.

\section{Fabrication of stone casts}

Figure 1 shows a stainless steel master cast designed to simulate an abutment tooth and a perforated metal tray adjusted to an impression thickness of $5 \mathrm{~mm}$. The master cast had an $8^{\circ}$ taper to the 
Table 1 Materials used in this study

\begin{tabular}{|c|c|c|c|c|}
\hline Code & Brand name & Manufacturer & Lot No. & $\mathrm{W} / \mathrm{P}(\mathrm{ml} / \mathrm{g})$ \\
\hline \multicolumn{5}{|c|}{ Agar impression material } \\
\hline $\mathrm{ARO}$ & Aromaloid & Omnico, Tokyo, Japan & $040601 \mathrm{G}$ & - \\
\hline AJI & Ajisai & Omnico, Tokyo, Japan & 040818E & - \\
\hline \multicolumn{5}{|c|}{ Alginate impression material } \\
\hline $\mathrm{ACZ}$ & Algiace Z & Dentsply-Sankin, Tokyo, Japan & $379-402$ & 2.27 \\
\hline \multicolumn{5}{|c|}{ Dental stone } \\
\hline - & New Plastone & GC, Tokyo, Japan & 0505091 & 0.24 \\
\hline \multicolumn{5}{|c|}{ Sodium hypochlorite } \\
\hline $\mathrm{SH}$ & Pureox & Oyalox, Tokyo, Japan & 3576 & - \\
\hline \multicolumn{5}{|c|}{ Glutaraldehyde } \\
\hline GA & Sterihyde & Maruishi Pharmaceutical, Osaka, Japan & 3X094 & - \\
\hline
\end{tabular}

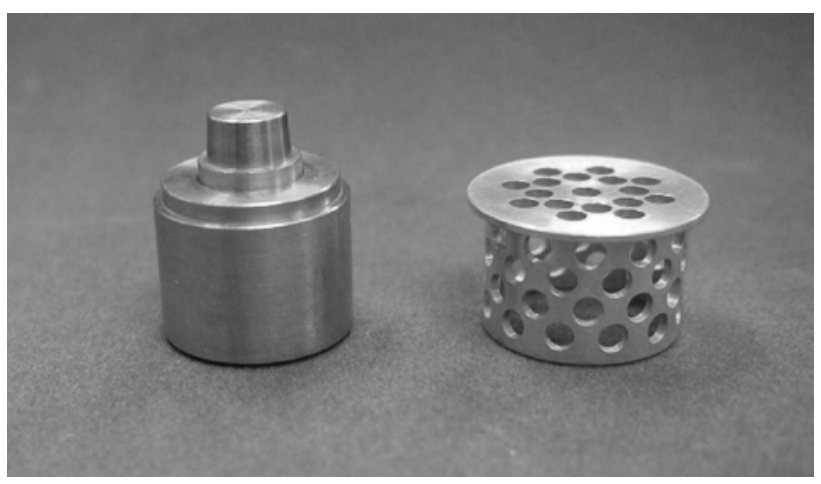

Fig. 1 Master cast (left) and tray (right).

vertical axis and a 1-mm-wide shoulder at the margin. Distance from the occlusal surface to the shoulder was $5 \mathrm{~mm}$. The upper surface was $8.3 \mathrm{~mm}$ in diameter and the lower portion was $9.0 \mathrm{~mm}$ in diameter.

The procedure for making the stone cast was as follows. The tray overfilled with mixed alginate impression material was seated on the master cast which was overlaid with one stick of agar sol. The combined agar/alginate impression was removed from the master cast five minutes after the start of alginate mixing, and then rinsed for 60 seconds under tap water.

After rinsing, the impressions were assigned to two groups. The first group was immersed in 1\% sodium hypochlorite solution for 10 minutes $^{3)}$ (ISH10; which was expected to have fewer adverse effects than 15-minute immersion in the same solution) or immersion in $2 \%$ glutaraldehyde solution for 30 minutes (IGA30). The second group was sprayed for 20 seconds so as to coat the impression surface with disinfectant solution. The impression sprayed with $1 \%$ sodium hypochlorite solution was stored in a

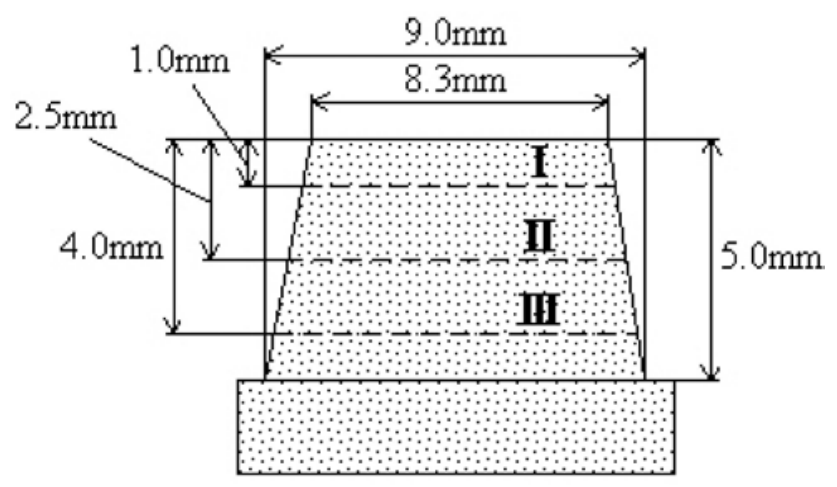

Fig. 2 Measurement positions on stone cast. Position I: $1.0 \mathrm{~mm}$ below, Position II: $2.5 \mathrm{~mm}$ below, Position III: $4.0 \mathrm{~mm}$ below the upper surface of stone cast.

sealed plastic bag for 10, 30, 60, and 120 minutes (SH10, SH30, SH60, SH120), and the impression sprayed with $2 \%$ glutaraldehyde solution was stored in a sealed plastic bag for 30, 60, and 120 minutes (GA30, GA60, GA120) with the impression surface turned downwards. After both modes of immersion and spray disinfection, the impressions were rinsed again for 60 seconds under tap water to remove all traces of the disinfectant solution.

Mixed stone was poured onto the surface of the impression mounted in a circular rubber mold of 15 $\mathrm{mm}$ height, and allowed to set at room temperature $\left(23 \pm 1^{\circ} \mathrm{C}\right)$. One hour after stone mixing, the stone cast was removed from the impression and stored at room temperature for 24 hours before dimensional change measurement. Five stone casts were prepared for each disinfecting condition. A stone specimen obtained from the impression, which was not treated after the first rinsing, was prepared as control (C). Temperature of the water used was $23 \pm 1^{\circ} \mathrm{C}$. 


\section{Measurement procedure}

As shown in Fig. 2, three measurement positions were set on the stone cast. Diameter of the stone cast was measured using a laser scan micrometer (LS-3060, Keyence, Tokyo, Japan) at each position namely, Position I: $1.0 \mathrm{~mm}$ below, II: $2.5 \mathrm{~mm}$ below, and III: $4.0 \mathrm{~mm}$ below the upper surface of stone cast. The mean of six measurements at each position was adopted as the representative value. Difference in diameter between the stone and master cast at each position was calculated as the dimensional change.

Dimensional change data were subjected to two-way analysis of variance with disinfection method and measurement position of stone cast for
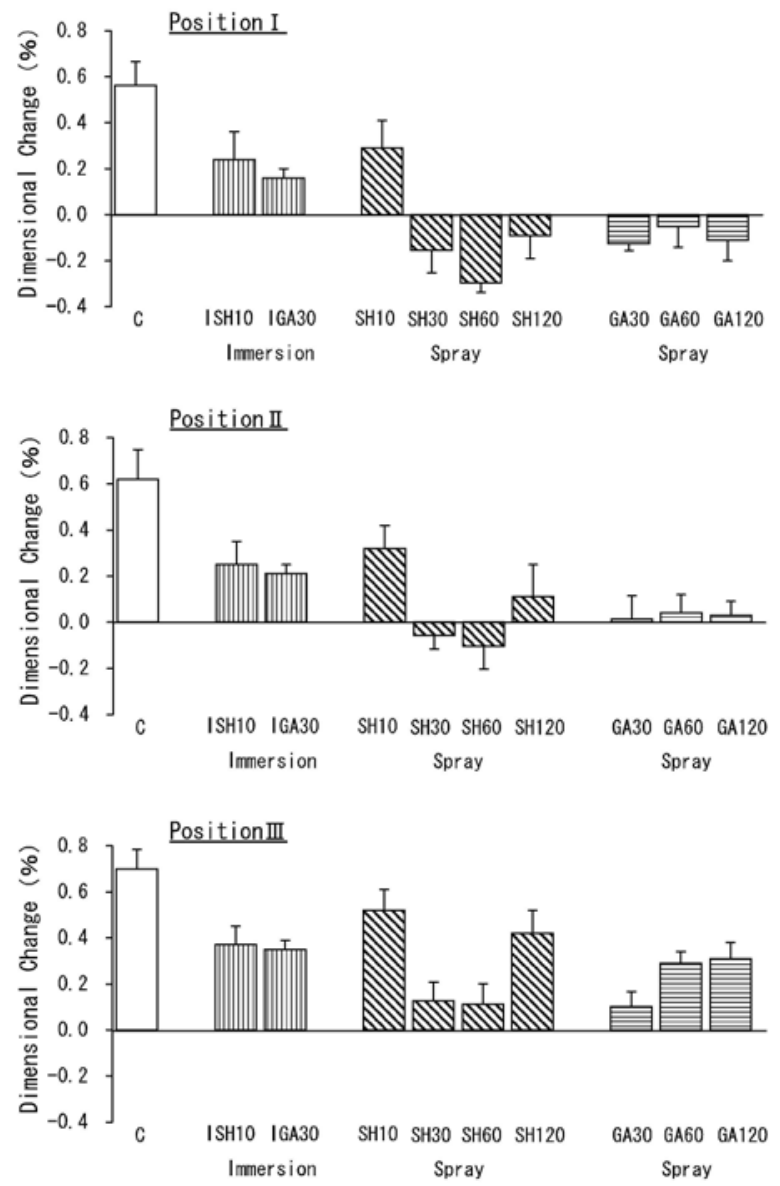

Fig. 3 Dimensional changes of stone casts (ARO-ACZ). C : Control; first rinsing only

ISH10: Immersion in $1 \%$ sodium hypochlorite for 10 minutes

IGA30: Immersion in $2 \%$ glutaraldehyde for 30 minutes

SH10 : Storage for 10 minutes, SH30: Storage for 30 minutes, SH60: Storage for 60 minutes, SH120: Storage for 120 minutes after spraying 1\% sodium hypochlorite

GA30 : Storage for 30 minutes, GA60: Storage for 60 minutes, GA120: Storage for 120 minutes after spraying $2 \%$ glutaraldehyde each impression as factors. The data were also subjected to Tukey's multiple comparison test $(\mathbf{a}=$ 0.05). The entire experiment was conducted at a room temperature of $23 \pm 1^{\circ} \mathrm{C}$ and a relative humidity of $50 \pm 5 \%$. The impression taking was done in an incubator (Atom, Tokyo, Japan), which was adjusted to a temperature of $35 \pm 1^{\circ} \mathrm{C}$ and a relative humidity of $95 \pm 5 \%{ }^{15)}$.

\section{RESULTS}

Figures 3 and 4 show the dimensional changes of stone casts obtained from the combined Aromaloid and Algiace $\mathrm{Z}$ impressions (ARO-ACZ) and the combined Ajisai and Algiace $\mathrm{Z}$ impressions (AJI-
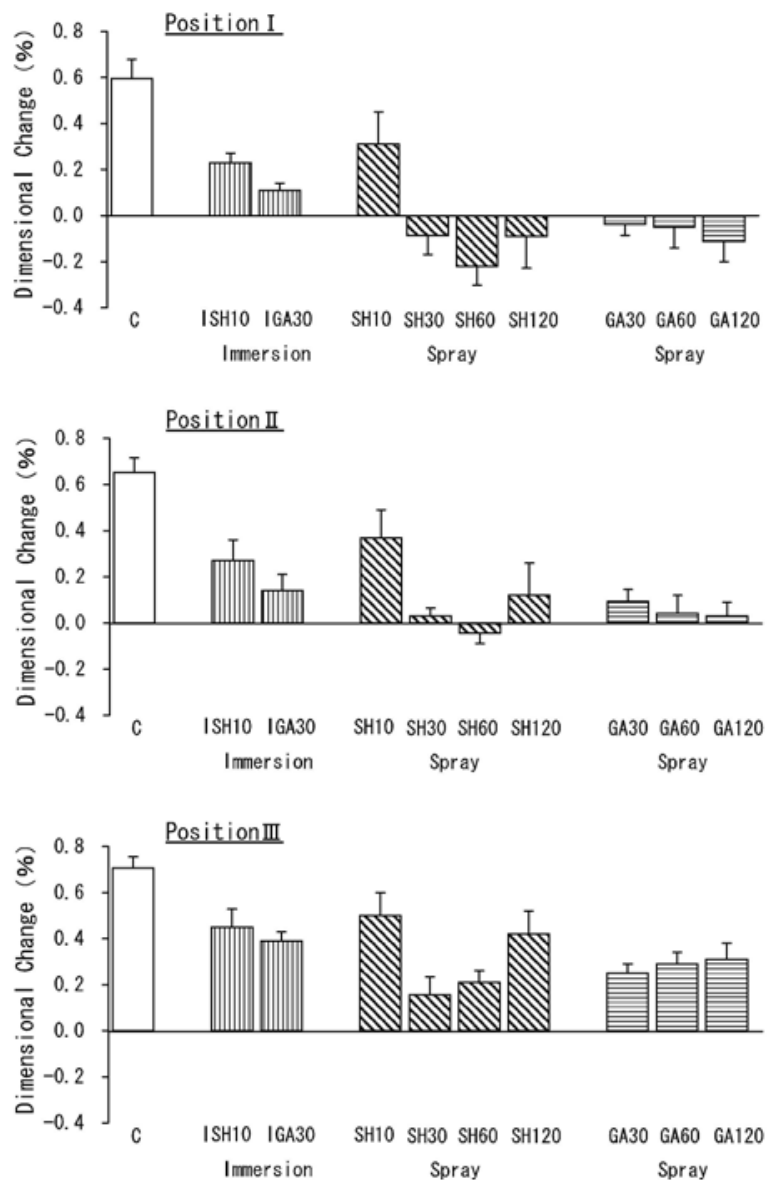

Fig. 4 Dimensional change of stone casts (AJI-ACZ). C : Control; first rinsing only

ISH10: Immersion in 1\% sodium hypochlorite for 10 minutes

IGA30: Immersion in $2 \%$ glutaraldehyde for 30 minutes

SH10 : Storage for 10 minutes, SH30: Storage for 30 minutes, SH60: Storage for 60 minutes, SH120: Storage for 120 minutes after spraying 1\% sodium hypochlorite

GA30 : Storage for 30 minutes, GA60: Storage for 60 minutes, GA120: Storage for 120 minutes after spraying $2 \%$ glutaraldehyde 
Table 2 Results of Tukey's multiple comparison tests for ARO-ACZ

\begin{tabular}{|c|c|c|c|c|c|c|c|c|c|c|c|c|c|}
\hline & \multicolumn{4}{|c|}{ Position I } & \multicolumn{4}{|c|}{ Position II } & \multicolumn{5}{|c|}{ Position III } \\
\hline $\mathrm{C}$ & & & & & & & & & & & & & e \\
\hline ISH10 & & & c & & & & $\mathrm{d}$ & e & & & $\mathrm{C}$ & d & \\
\hline IGA30 & & & c & & & c & $\mathrm{d}$ & e & & & $c$ & d & \\
\hline SH10 & & & c & & & & & e & & & & d & \\
\hline SH30 & a & b & & d & b & & & & $\mathrm{a}$ & b & & & \\
\hline SH60 & a & & & $\mathrm{a}$ & & & & & $\mathrm{a}$ & & & & \\
\hline SH120 & & $b$ & & & b & c & $\mathrm{d}$ & & & & $c$ & d & \\
\hline GA30 & a & b & & $\mathrm{a}$ & b & c & & & $\mathrm{a}$ & & & & \\
\hline GA60 & & b & & $\mathrm{a}$ & $\mathrm{b}$ & c & & & & b & $\mathrm{c}$ & & \\
\hline GA120 & a & $b$ & & $\mathrm{a}$ & $\mathrm{b}$ & c & & & & & $c$ & & \\
\hline
\end{tabular}

Same small letter at each position means no significant difference.

Table 3 Results of Tukey's multiple comparison tests for AJI-ACZ

\begin{tabular}{|c|c|c|c|c|c|c|c|c|c|c|}
\hline & \multicolumn{4}{|c|}{ Position I } & \multicolumn{2}{|c|}{ Position II } & \multicolumn{4}{|c|}{ Position III } \\
\hline $\mathrm{C}$ & & & & & & & & & & e \\
\hline ISH10 & & & $\mathrm{c}$ & $\mathrm{d}$ & $c$ & & & c & d & \\
\hline IGA30 & & $\mathrm{b}$ & $\mathrm{c}$ & & & & b & c & d & \\
\hline SH10 & & & & $\mathrm{d}$ & c & & & & d & \\
\hline SH30 & $\mathrm{a}$ & & & & & $\mathrm{a}$ & & & & \\
\hline SH60 & $\mathrm{a}$ & & & & & $\mathrm{a}$ & & & & \\
\hline SH120 & $\mathrm{a}$ & & & & & & b & c & $\mathrm{d}$ & \\
\hline GA30 & $\mathrm{a}$ & $\mathrm{b}$ & & & & $\mathrm{a}$ & $\mathrm{b}$ & & & \\
\hline GA60 & $\mathrm{a}$ & & & & & $\mathrm{a}$ & $\mathrm{b}$ & c & $\mathrm{d}$ & \\
\hline GA120 & $\mathrm{a}$ & & & & & $\mathrm{a}$ & $\mathrm{b}$ & c & & \\
\hline
\end{tabular}

Same small letter at each position means no significant difference.

ACZ), respectively. Results of two-way ANOVA showed that the disinfection method and measurement position, and the interaction of these two factors were significant $(\mathbf{a}=0.01)$. Results of Tukey's multiple comparison test at each measurement position are shown in Tables 2 and 3 .

The dimensional changes at each position of both ARO-ACZ and AJI-ACZ were significantly smaller than that of the control under all disinfecting conditions.

Stone casts obtained from impressions treated by immersion disinfection (ISH10 and IGA30) showed no significant differences in dimensional change at all measurement positions.

As for the spray method with $1 \%$ sodium hypochlorite solution, dimensional changes at Positions I and II had no significant differences among SH30, SH60, and SH120, except for SH60 and SH120 of ARO-ACZ. There were significant differences between SH10 and the other disinfecting conditions. At Position III, SH10 was significantly different from SH30 and SH60. As for the spray method with $2 \%$ glutaraldehyde solution, there were no significant differences among GA30, GA60, and GA120 at all positions, except at Position III of ARO-ACZ. The disinfectant type did not significantly influence dimensional change at all positions for the same storage period, except at Positions I and III of ARO-ACZ after being stored for 60 minutes following spraying.

As for the disinfection method, there were no significant differences between ISH10 and SH10 at all positions for either impression. However, there were significant differences between IGA30 and GA30 at 
Positions I and III of ARO-ACZ.

\section{DISCUSSION}

It is recommended that impressions be disinfected by immersion in glutaraldehyde or sodium hypochlorite solution or by storage in sealed bags after being sprayed with these disinfectant solutions ${ }^{1,3)}$.

For alginate impressions, short-term immersion in $1 \%$ sodium hypochlorite solution ${ }^{3)}$ or storage in a sealed bag after spraying with glutaraldehyde or sodium hypochlorite solution ${ }^{1)}$ have been recommended. These disinfection methods have been clinically used because they have no serious adverse effects on the dimensional accuracy of resultant stone casts $^{3,16)}$. However, information is scarce concerning the spray disinfection method for combined agar/alginate impressions. The present study investigated the effects of spray disinfection of combined agar/alginate impressions on the dimensional change of resultant stone casts, comparing the effects against those of immersion disinfection.

In the present study, the agar sol layer was thin at the upper portion of the master cast and thick at the lower portion. This was because the alginate mix pushed the agar sol toward the lower portion of the master cast when the tray overfilled with mixed alginate impression material was seated on the master cast overlaid with agar sol. In the case of immersion disinfection of combined agar/alginate impressions, the stone cast was smaller than that of the control because both agar and alginate impressions swelled due to water absorption. Alginate impressions swell more in water than agar impressions $\mathrm{s}^{17,18)}$. Consequently, the difference in the dimensional change from the control at Position I, where the layer of alginate impression was thick, was greater than that at Position III.

In the case of spray disinfection of impressions, the dimensional accuracy of stone casts was affected by the dimensional change of impressions during storage after spraying with disinfectants ${ }^{7,8}$. Both agar and alginate impressions contract in $100 \%$ relative humidity ${ }^{17,18}$. As the alginate impression that was supported by a tray contracted toward the tray, the diameter of the stone cast would be greater ${ }^{19}$. However, it was uncertain which direction the agar impressions contracted, as they were supported by the elastic alginate impression. In the present study, the dimensional changes of stone casts obtained from the sprayed impressions were significantly smaller than that of the control. When the treatment period was the same (IGA30 and GA30), the dimensional changes of stone casts obtained from impressions disinfected by spray tended to be smaller than those obtained from impressions disinfected by immersion. There were significant differences arising from the disinfection methods at Positions I and III of AROACZ. It could be concluded that the contraction of agar impression caused the decrease in diameter of the stone cast, when the combined impression was disinfected by spray.

For the spray method with $1 \%$ sodium hypochlorite solution, there were no significant differences arising from storage period, except for SH60 and SH120 of ARO-ACZ, though there were significant differences between the 10-minute storage and the other storage periods at Positions I and II. At Position III, the 10-minute storage was significantly different from the 30- and 60-minute storage periods. For the spray method with $2 \%$ glutaraldehyde solution, there were no significant differences arising from storage period at all positions, except at Position III of ARO-ACZ. Contraction of the agar impression in $100 \%$ relative humidity increased within the first 15 minutes ${ }^{17}$. Conversely, the amount of contraction of ACZ impression in $100 \%$ relative humidity for two hours was minimal ${ }^{7}$. It was considered that the combined impression tested in the present study contracted during storage within the first 10 minutes and then stabilized in size after 30 minutes. For the stone cast obtained from impressions that were stored for 120 minutes after spraying with $1 \%$ sodium hypochlorite, dimensional change at Position III was slightly different from that of the control. This might be due to the chemical effects of sodium hypochlorite on agar impression and an accelerated contraction of the alginate impression.

The effect of immersion disinfection on stone casts was less than that of spray disinfection except for the 10-minute storage. The 10-minute storage had little effect on the diameter of stone cast. When the storage period was beyond 30 minutes, there were no significant differences in dimensional change of stone casts at most positions. The diameter of stone cast was also stable during long-term storage. However, combined agar/alginate impressions should not be stored beyond 30 minutes, as this led to a large difference in dimensional change from the control.

For both impressions, disinfectant type did not play a significant role in immersion disinfection. However, there were reports ${ }^{9,10}$ that the immersion of impressions in glutaraldehyde for 30 minutes largely affected the dimensional accuracy of the resultant stone cast due to expansion of the alginate impression.

In summary, it was found that storage for 10 minutes after spraying with $1 \%$ sodium hypochlorite was an appropriate disinfection method for combined agar/alginate impressions, as well as immersion in $1 \%$ sodium hypochlorite for 10 minutes. 


\section{ACKNOWLEDGEMENTS}

This study was supported in part by the Sato Fund, Nihon University School of Dentistry.

\section{REFERENCES}

1) Council on Dental Materials, Instruments, and Equipment, Council on Dental Practice, Council on Dental Therapeutics. Infection control recommendations for the dental office and the dental laboratory. J Am Dent Assoc 1988; 116:241-248.

2) Council on Dental Materials, Instruments, and Equipment. Disinfection of impressions. J Am Dent Assoc 1991; 122:110.

3) Blair FM, Wassell RW. A survey of the methods of disinfection of dental impressions used in dental hospitals in the United Kingdom. Br Dent J 1996; 180:369-375.

4) Hiraguchi $H$, Nakagawa $H$, Uchida $H$, Tanabe N. Influences of immersion of impressions in disinfectant solutions on the surface roughness of stone models: Comparison of commercially available hydrocolloid impression materials. Japan J Conserv Dent 2002; 45:29-38.

5) Hiraguchi H, Nakagawa $H$, Uchida H, Tanabe N. Disinfection of impressions in dental treatment for elderly patients at home - Effect of $\mathrm{W} / \mathrm{P}$ ratio of alginate impression materials on the dimensional accuracy and deformation of stone models. J J Dent Mater 2002; 21:313-322.

6) Hiraguchi H, Nakagawa H, Uchida H, Tanabe N. Effects of rinsing alginate impressions using acidic electrolyzed water on dimensional change and deformation of stone models. Dent Mater J 2003; 22:494506.

7) Hiraguchi H, Nakagawa H. Storage of impressions following spray with disinfectant solutions in dental treatment for elderly patients at home. Part 1: Effect of long-term storage of alginate impressions in sealed bag on the dimensional accuracy and deformation of stone models. J J Gerodont 2004; 18:309-316.

8) Hiraguchi H, Nakagawa H, Wakashima M, Miyanaga K, Sakaguchi S, Nishiyama M. Effects of storage period of alginate impressions following spray with disinfectant solutions on the dimensional accuracy and deformation of stone models. Dent Mater J 2005;
$24: 36-42$.

9) Hiraguchi $H$, Uchida $H$, Nakagawa $H$, Tanabe $N$, Habu H. Effects of immersion disinfection of agaralginate combined impressions on the reproducibility of stone models. J J Dent Mater 1998; 17:80-95.

10) Habu H, Uchida H. Agar/alginate combined impression systems - Effects of immersion in disinfectant solutions. J J Dent Mater 1998; 17:231-237.

11) Uchida $H$, Hiraguchi $H$, Nakagawa $H$, Tanabe $N$. Dimensional accuracy of dies and fit of cast crowns obtained from combined agar/alginate impressions disinfected by sodium hypochlorite. Japan J Conserv Dent 2004; 47:70-79.

12) Bergman B, Bergman M, Olsson S. Alginate impression materials, dimensional stability and surface detail sharpness following treatment with disinfectant solutions. Swed Dent J 1985; 9:255-262.

13) Olsson S, Bergman B, Bergman M. Agar impression materials, dimensional stability and surface detail sharpness following treatment with disinfectant solutions. Swed Dent J 1987; 11:169-177.

14) Tan HK, Hooper PM, Buttar IA, Wolfaardt JF. Effects of disinfecting irreversible hydrocolloid impressions on the resultant gypsum casts. Part II: Dimensional changes. J Prosthet Dent 1993; 70:532537.

15) International Organization for Standardization. ISO 13716:1999, Dentistry - Reversible-irreversible hydrocolloid impression material systems.

16) Muller-Bolla M, Lupi-Pegurier L, Velly AM, Bolla M. A survey of disinfection of irreversible hydrocolloid and silicone impressions in European Union dental schools: Epidemiologic study. Int J Prosthodont 2004; 17:165-171.

17) Habu H, Hashimoto H, Nomata H, Ohta T, Nitta H. Dimensional stability of reversible hydrocolloid (agar) impression materials. J J Dent Mater 1987; 6:837-845.

18) Habu H, Uchida H, Akiyama J, Nakano K. Dimensional stability of conventional and dustless alginate impression materials. J J Dent Mater 1986; 5:47-53.

19) Hiraguchi H, Nitta H, Kohno H, Habu H. A three-dimensional study of the reproducibility of stone casts obtained from alginate impressions. Part I: Effects of temperature during setting, storage environment and storage time of impression on dimensional accuracy. J J Dent Mater 1991; 10:22-29. 